\title{
The Role of Consumption Substitutability in the International Transmission of Shocks.*
}

\author{
Cédric Tille ${ }^{\dagger}$
}

March 4, 1999

\begin{abstract}
This paper develops a general framework to analyze the welfare consequences of monetary and fiscal shocks in an open economy, focusing on the role of the degree of substitutability between goods produced in different countries. We find that an expansionary shock that would be beneficial in a closed economy can have an adverse 'beggar-thyself' effect in the country where it takes place, or an adverse 'beggar-thy-neighbor' effect on its neighbor. Such effects depend significantly on the degree of substitutability between goods produced in different countries, as well as the exact nature of the shocks. In addition, a closed economy can be an imperfect approximation of a large open economy when there is little substitutability between goods produced in different countries.
\end{abstract}

JEL classification: F41, F42

Keywords: Marshall-Lerner-Robinson condition, Beggar-thy Neighbor

${ }^{*}$ This paper is a revised version of the third chapter of my Ph.D. dissertation. I am grateful to Ben Bernanke, Giancarlo Corsetti, Paolo Pesenti, Kenneth Rogoff and Michael Woodford for helpful guidance and comments. I also thank the participants of Federal Reserve Fall International System Committee Meeting, as well as seminar audiences at the Federal Reserve Bank of New York, Yale University, and the International Monetary Fund for valuable feedback. All remaining errors and omissions are of course mine. This paper reflects the views of the author and not necessarily the views of the Federal Reserve Bank of New York or the Federal Reserve.

${ }^{\dagger}$ Federal Reserve Bank of New York. (212) 720-5644, Cedric.Tille@ny.frb.org 


\section{Introduction}

A central issue in open macroeconomics is the transmission of shocks from a country to its neighbors. In particular, the possibility of an adverse 'beggar-thy-neighbor' problem, where an expansion in a country comes at the expense of the others, has long been considered to be a worrisome possibility, as first discussed by Nurkse (1944). ${ }^{1}$

Despite the central place of the beggar-thy-neighbor concept in the debate, our understanding of it is remarkably limited, and often involves more of an intuitive exposition than a thorough analysis. Even then, the analysis is based on the standard Mundell-Fleming-Dornbusch setup which lacks an explicit welfare metric and therefore isn't well equipped to address a welfare concept such as the beggar-thy-neighbor problem.

The limitations of an analysis based on an ad-hoc welfare criterion can be avoided by using a setup built on micro foundations which offers a clear welfare criterion, such as the utility of the representative consumer. The 'new open economy macroeconomics' framework based on the contributions by Obstfeld and Rogoff $(1996,1995)$ offers such a setup, which combines micro foundations and market imperfections in the form of monopolistic competition and rigid prices. In such a model, a monetary expansion is welfare improving, as it moves the economy away from the suboptimal market equilibrium towards the competitive first best. One of the most interesting findings is that there is no beggar-thy-neighbor problem as the expansion is equally beneficial to all countries. ${ }^{2}$

The analysis by Obstfeld and Rogoff however assumes that the elasticity of substitution between two goods produced in the same country is the same as the elasticity of substitution between two good produced in different countries. Such an assumption pins down the sensitivity of the consumption switching effect through which changes in the terms of trade generate a reallocation of consumption between home and foreign goods. This appears to restrict the welfare analysis, as this sensitivity plays a central role

\footnotetext{
${ }^{1}$ A similar concern can be found in analyses of the recent Asian crisis, such as Fernald, Adison and Lougani (1998).

${ }^{2}$ The model has been extended in several directions, to assess the role of pricing-tomarket (Betts and Devereux (1997)-(1996a), Tille (1998a)), home bias (Warnock (1998)), non-traded goods (Hau (1998)), transportation costs (Zhu (1998)), as well as undertake an analysis in a stochastic setup (Devereux and Engel (1998), Obstfeld and Rogoff (1998)). A recent survey is provided by Lane (1998).
} 
by determining the extent to which a change in the terms of trade affects the sales revenue of the agents, hence consumption, through the usual MarshallLerner-Robinson argument.

If countries specialize in the production of certain categories of goods, there is likely to be less substitutability between goods produced in different countries than between goods produced in a given country. Although the former is difficult to estimate, Backus, Kehoe and Kydland (1994a,b) argue that it is in the range of $1-2$, which is a much smaller value than the usual estimates for the elasticity of substitution between goods produced in the same country, which is about 6 as in Rotemberg and Woodford (1992). ${ }^{3}$

The main contribution of this paper is to extend the baseline ObstfeldRogoff model to allow the degree of substitutability across countries to differ from the degree of substitutability within countries, and assess the consequences on the model results, with a focus on the welfare dimension. We do not take a stand on the value of the elasticity of substitution across countries, and the results are presented for a wide range of values. The paper also presents the analysis in a simple graphical setup, illustrating the channels at work.

The major result of the analysis is that a monetary expansion does not benefit all countries to the same extent. If there is less substitutability across countries than within countries, which is the most likely case, a monetary expansion in a country can have an adverse 'beggar-thyself' effect on that country, while benefiting its neighbor. Intuitively, the low value of the elasticity of substitution across countries limits the extent of the consumption switching effect induced by the worsening of the terms of trade. On the other hand, residents cannot easily substitute away from imports which are now much more expensive. The adverse beggar-thyself effect is more acute the smaller the country, the lower the elasticity of substitution across countries and the smaller the monopolistic distortion. By contrast, a fiscal expansion always has a beggar-thy-neighbor effect, especially if there is little substitutability across countries. Intuitively, the higher demand faced by the producers in the expanding country induces them to raise their prices, thereby worsening the terms of trade for the residents of the other country.

\footnotetext{
${ }^{3}$ The only extensions of the Obstfeld-Rogoff model that considers a different substitutability between goods produced in different countries are Corsetti and Pesenti (1997), Devereux and Engel (1998) and Obstfeld and Rogoff (1998). They however focus on the effects of large shocks, and do not explore the consequences of a different substitutability in details.
} 
The paper is organized as follows: the model used is presented in Section 2, and the effects of unexpected shocks are analyzed in Section 3. As the framework is very similar to the one in Obstfeld and Rogoff $(1996,1995)$, the technical aspects are presented in the Appendix. Section 4 assesses whether shocks can adversely affect the country where they take place, or its neighbor. The findings are illustrated in a numerical example in Section 5, and Section 6 concludes.

\section{A Model with Different Elasticities of Sub- stitution}

This section presents the framework used in the analysis, which is an extension of Obstfeld and Rogoff's (1996, 1995). For brevity, the exposition focuses on the main aspects of the model, as well as the innovation relative to their contribution, to which we refer the reader for a more detailed exposition of the setup.

\subsection{The Setup}

The world is made of two countries, home and foreign, and is populated by a continuum of consumers. We normalize the world size to 1 , and consider the first $n$ consumers to be residents of the home country. All consumers in the world have identical preferences over consumption, real balances, domestic government spending and effort. The intertemporal objective of a home consumer, indexed by $k$, at time $t$ is given by:

$$
U_{k, t}=\sum_{s=0}^{\infty} \beta^{s}\left\{\frac{C_{k, t+s}^{1-\frac{1}{\sigma}}}{1-\frac{1}{\sigma}}+\gamma \ln \left(\frac{M_{k, t+s}}{P_{t+s}}\right)+F\left(G_{t+s}\right)-\frac{\kappa}{1+\varpi} Y_{k, t+s}^{1+\varpi}\right\}
$$

where $C_{k}$ is a consumption basket defined below, $M_{k}$ the nominal balances, $P$ the consumer price index, and $G$ the home government spending per capita. ${ }^{4}$ The consumer is also the sole producer of the particular brand $k$ included in all consumers' baskets. Producing an amount $Y_{k}$ of this brand

\footnotetext{
${ }^{4}$ The inclusion of government spending in the consumer's utility is done only to clarify the welfare implications of fiscal shocks, as discussed below. The case where government spending is wasteful is simply given by setting $F(G)=0$.
} 
involves a costly effort captured by the last term in (1). We assume that the cost of effort is convex $(\varpi>0)$. The overall consumption basket, $C_{k}$, is a CES aggregate of a basket of goods produced in the home country, $C_{k}^{h}$, and a basket of goods produced in the foreign country, $C_{k}^{f}$ :

$$
C_{k}=\left[n^{\frac{1}{\rho}}\left(C_{k}^{h}\right)^{\frac{\rho-1}{\rho}}+(1-n)^{\frac{1}{\rho}}\left(C_{k}^{f}\right)^{\frac{\rho-1}{\rho}}\right]^{\frac{\rho}{\rho-1}}
$$

where $\rho>0$ is the elasticity of substitution between home and foreign goods, which we refer to as the cross-country substitutability. Each country specific basket, $C_{k}^{h}$ and $C_{k}^{f}$, is in turn a CES aggregate across the brands produced in the home and foreign country respectively:

$$
C_{k}^{h}=\left[n^{-\frac{1}{\theta}} \int_{0}^{n}\left(C_{k}^{h}(z)\right)^{\frac{\theta-1}{\theta}} d z\right]^{\frac{\theta}{\theta-1}}, C_{k}^{f}=\left[(1-n)^{-\frac{1}{\theta}} \int_{n}^{1}\left(C_{k}^{f}(z)\right)^{\frac{\theta-1}{\theta}} d z\right]^{\frac{\theta}{\theta-1}}
$$

where $\theta>1$ is the elasticity of substitution between two goods produced in the same country, which we refer to as the within-country substitutability. $C_{k}^{h}(z)$ and $C_{k}^{f}(z)$ denote the consumption of a particular brand $z$ produced in the home and the foreign country respectively. The assumption that $\theta$ is larger than 1 ensures that the equilibrium solution is well defined.

The central feature of this paper is to allow the cross-country and withincountry substitutability to differ. If $\rho \leq \theta$, there is less substitutability across countries than within countries, because of specialization for example. ${ }^{5}$ The contributions by Betts and Devereux (1997, 1996a,b), Obstfeld and Rogoff (1996, 1995), and Tille (1998a) focus on the case where $\rho=\theta$, whereas Corsetti and Pesenti (1997) consider the case where $\rho=1$.

The allocation of consumption across the available brands is derived in the usual way and the results are indcated in Table $1 .^{6}$ The prices faced by a home consumer are defined as follows: $P^{h}(z)$ and $P^{f}(z)$ are the prices of a home and foreign brand $z$, respectively, $P^{h}$ and $P^{f}$ are the price indexes of home and foreign goods, respectively, and $P$ is the consumer price index. The definitions for the prices in the foreign country are similar, foreign

\footnotetext{
${ }^{5}$ Consumers first allocate their consumption across broad categories of goods, such as cars and textiles, and then across the various brands within each category. In our model, we assume that countries specialize, matching each country with a particular category. The analysis of a richer setup where each country produces both categories, albeit to a different extent, along the lines of Faruqee (1996), is left for future work.

${ }^{6}$ This dimension of the problem being static, we omit the time subscripts for covenience.
} 
variables being denoted by an asterisk. The price indexes are of the usual cost-minimizing form.

Table 1: Consumption demands

$\begin{aligned} C_{k}^{h}(z \in[0, n]) & =\left[\frac{P^{h}(z)}{P^{h}}\right]^{-\theta}\left[\frac{P^{h}}{P}\right]^{-\rho} C_{k} \\ C_{k}^{f}(z \in(n, 1]) & =\left[\frac{P^{f}(z)}{P^{f}}\right]^{-\theta}\left[\frac{P^{f}}{P}\right]^{-\rho} C_{k} \\ C_{k}^{* h}(z \in[0, n]) & =\left[\frac{P^{* h}(z)}{P^{* h}}\right]^{-\theta}\left[\frac{P^{* h}}{P^{*}}\right]^{-\rho} C_{k}^{*} \\ C_{k}^{* f}(z \in(n, 1]) & =\left[\frac{P^{* f}(z)}{P^{* f}}\right]^{-\theta}\left[\frac{P^{* f}}{P^{*}}\right]^{-\rho} C_{k}^{*}\end{aligned}$

Our focus being the role played by the cross-country elasticity of substitution $\rho$, we assume that the law of one price holds for simplicity. Denoting the nominal exchange rate (units of home currency per foreign currency) as $S$, this implies that $P^{h}(z)=S P^{* h}(z), P^{f}(z)=S P^{* f}(z)$. It is then straightforward to show that the purchasing power parity also holds: $P=S P^{*}$. A more complex analysis allowing for deviations from the law of one price can be undertaken, following Betts and Devereux (1997, 1996a,b). Such an analysis is presented in a companion paper (Tille, 1998b).

We consider that each consumer can hold two assets: a nominal bond denominated in the home country currency, ${ }^{7}$ and the currency of her country of residence. The intertemporal solution of the consumer problem is standard and is given by:

$$
\begin{aligned}
C_{k, t}^{-\frac{1}{\sigma}} & =\beta\left(1+i_{t+1}\right) \frac{P_{t}}{P_{t+1}} C_{k, t+1}^{-\frac{1}{\sigma}} \\
\frac{M_{k, t}}{P_{t}} & =\gamma C_{k, t}^{\frac{1}{\sigma}} \frac{1+i_{t+1}}{i_{t+1}}
\end{aligned}
$$

(2) is the Euler condition for the intertemporal allocation of consumption and (3) is the money demand.

Following Corsetti and Pesenti (1997), and Obstfeld and Rogoff (1998), government spending captures a source of demand that is limited to domestically produced goods. Fiscal shocks can then be interpreted as shifting the demand curve faced by producers in a country, while leaving the demand curve faced by producers in the other country unchanged. We denote the per

\footnotetext{
${ }^{7}$ The results would be identical if we were to consider a real bond, as in Obstfeld and Rogoff $(1996,1995)$, or a nominal bond denominated in the foreign currency.
} 
capita real purchases of the government in the home country by $G$, and assume that they are allocated across the various domestic brands in the same way as private consumption, as described in table 1. As Ricardian equivalence holds in our setup, we assume that the government balances its budget each period, financing its purchases through lump-sum taxes and seignorage.

We now analyze the optimal price setting by a producer for the brand she sells. A home [foreign] producer $k$ chooses a price $P^{h}(k)\left[P^{* f}(k)\right]$ denominated in her own currency. As brands are imperfect substitutes, the producer has some monopoly power, which she takes into account in her optimal choice. The demand for her brand is obtained by aggregating private purchases across all consumers in the world and government purchases, and is given by:

$$
\begin{aligned}
Y_{k} & =\left[\frac{P^{h}(k)}{P^{h}}\right]^{-\theta}\left\{\left[\frac{P^{h}}{P}\right]^{-\rho} C^{w}+G\right\} \\
Y_{k}^{*} & =\left[\frac{P^{* f}(k)}{P^{* f}}\right]^{-\theta}\left\{\left[\frac{P^{* f}}{P^{*}}\right]^{-\rho} C^{w}+G^{*}\right\}
\end{aligned}
$$

where $C^{w}=n C+(1-n) C^{*}$ is the worldwide consumption, and $C=$ $\frac{1}{n} \int_{0}^{n} C_{k} d k, C^{*}=\frac{1}{1-n} \int_{n}^{1} C_{k}^{*} d k$ are the per capita consumptions in the home and foreign country respectively. (4)-(5) show that the elasticity of the demand faced by a producer with respect to her own price is the within-country elasticity of substitution $\theta$, and not the cross-country elasticity of substitution $\rho$. The optimal prices can be computed as:

$$
\frac{P^{h}(k)}{P}=\frac{\theta \kappa}{\theta-1} Y_{k}^{\varpi} C_{k}^{\frac{1}{\sigma}}, \frac{P^{* f}(k)}{P^{*}}=\frac{\theta \kappa}{\theta-1} Y_{k}^{* \varpi} C_{k}^{* \frac{1}{\sigma}}
$$

(6) shows that the marginal utility of one dollar spent on consumption, $C_{k}^{-\frac{1}{\sigma}} P^{-1}$, exceeds the marginal cost of generating it through producing and selling output, $\kappa Y_{k}^{\varpi}\left(P^{h}(k)\right)^{-1}$, by a markup equal to $\theta(\theta-1)^{-1}>1$, as noted by Bachetta and van Wincoop (1998). The markup is determined by $\theta$ as it is the elasticity of demand with respect to the producer's own price.

A central feature of our setup is that (6) does not necessarily hold. Following Obstfeld and Rogoff (1996, 1995), we assume that prices are set one period in advance. Following a shock, prices cannot be adjusted in the short 
run and output is determined by the demands (4)-(5). ${ }^{8}$ In the long run, producers adjust their prices, and (6) holds.

All consumers within a country being identical, individual variables are equal to per capita variables. We denote the representative home consumer's bond holdings at the begining of period $t$ by $B_{t}$, and the nominal interest rate on these holdings by $i_{t}$. As the bond is in zero net supply worldwide, we can write the current-account equations as:

$$
\begin{aligned}
\frac{B_{t+1}}{P_{t}}+C_{t}+\frac{P_{t}^{h}}{P_{t}} G_{t} & =\left(1+i_{t}\right) \frac{B_{t}}{P_{t}}+\frac{P_{t}^{h}}{P_{t}} Y_{t} \\
-\frac{n}{1-n} \frac{B_{t+1}}{S_{t} P_{t}^{*}}+C_{t}^{*}+\frac{P_{t}^{* f}}{P_{t}^{*}} G_{t}^{*} & =-\left(1+i_{t}\right) \frac{n}{1-n} \frac{B_{t}}{S_{t} P_{t}^{*}}+\frac{P_{t}^{* f}}{P_{t}^{*}} Y_{t}^{*}
\end{aligned}
$$

The model being non linear, we first derive the solution for a symmetric steady state, and then analyze the model in terms of percentage deviations from this steady state.

\subsection{Symmetric Steady State and Percentage Devia- tions}

We focus on a symmetric steady state where no country has any net claims on the other: $B=B^{*}=0$, and government spending per capita are equal in both countries: $G=G^{*}=G_{0}$. As in any steady state, the interest rate reflects the discount factor, and is equal to $\beta^{-1}-1$. All residents in both countries are identical, consume an amount $C_{0}$, and produce an amount $C_{0}+G_{0}$. The steady state consumption is uniquely given by the optimal price setting (6) and is suboptimally low as the marginal utility of consumption exceeds the marginal cost of production, because of monopolistic competition.

In our analysis, we consider the effect of unexpected shocks, and rewrite all variables as linear approximations around the symmetric steady state. For most variables, a lower case denotes the percentage deviation from the symmetric steady state:

$$
x=\frac{X-X_{0}}{X_{0}}
$$

\footnotetext{
${ }^{8}$ As we consider small shocks, producers always accommodate an additional demand, because their price is above their marginal cost.
} 
The exceptions are per capita consumption and government spending, which are scaled by the symmetric steady state output $Y_{0}=C_{0}+G_{0}$, and bond holdings, which are scaled by nominal output:

$$
c=\frac{C-C_{0}}{Y_{0}}, g=\frac{G-G_{0}}{Y_{0}}, c^{*}=\frac{C^{*}-C_{0}}{Y_{0}}, g^{*}=\frac{G^{*}-G_{0}}{Y_{0}}, b=\frac{B}{P_{0} Y_{0}}
$$

where $c_{0}=C_{0} / Y_{0}$ is the consumption-output ratio in the symmetric steady state.

\section{A Graphical Solution of the Impact of Un- expected Shocks}

This section derives the consequences of unexpected monetary and fiscal shocks in the model, illustrating then with a simple graphical apparatus. Following Obstfeld and Rogoff $(1996,1995)$, we consider that the economy is initially at the symmetric steady state characterized above and agents do not expect any kind of shocks. When an unexpected shock occurs, prices are preset and cannot be adjusted in the short run. In the long run, they are adjusted and the economy reaches a new steady state. The short and long run solutions are written in terms of percentage deviations from the initial steady state, and long run values are denoted by an upper bar (for example, the effect on consumption in the home country is denoted by $c$ in the short run and $\bar{c}$ in the long run).

The cross-country substitutability $\rho$ plays a central role in the analysis. Intuitively, it captures the sensitivity of the allocation between home and foreign goods with respect to the terms of trade, defined as the relative price of home and foreign goods. As shown in the Appendix, the crosscountry substitutability affects the distribution of a shock's impact across countries, but not the worldwide impact. The results in this section are therefore presented and discussed in terms of cross country differences for simplicity. This aspect should be kept in mind in interpreting our results. ${ }^{9}$

The role of the cross-country substitutability reflects the usual MarshallLerner-Robinson condition, and determines whether the consumption switching towards (away from) home goods following a worsening (improvement)

\footnotetext{
${ }^{9}$ For example, the mention of an increase in output in the home country should be interpreted as an increase relative to output in the foreign country, and not necessarily an increase in absolute terms.
} 
of the home terms of trade is large enough to increase (decrease) the sales revenue of home producers, relative to foreign producers. To highlight this point, we divide the range of possible values of $\rho$ in two intervals:

- $\rho>1$ : goods produced in different countries are close substitutes and the Marshall-Lerner-Robinson condition holds, a case that we refer to as MLR. A worsening in the terms of trade generates a large consumption switching towards home goods and the sales revenue of home producers increases.

- $\rho<1$ : goods produced in different countries are poor substitutes and the Marshall-Lerner-Robinson condition does not hold, a case referred to as NON-MLR. A worsening of the terms of trade results in a negligible switching towards home goods, and the sales revenue decreases. ${ }^{10}$

We consider permanent monetary $\left(m=\bar{m}, m^{*}=\bar{m}^{*}\right)$ and fiscal $(g=$ $\left.\bar{g}, g^{*}=\bar{g}^{*}\right)$ shocks. ${ }^{11}$ Monetary shocks are analyzed, as they play a nonnegligible role in the short run volatility of the exchange rate, according to Rogers (1997). Fiscal shocks are introduced to capture a source of demand that falls only on the goods of one country.

\subsection{Two Relations between Output and Consumption}

We start by evaluating the impact of monetary and fiscal shocks on output and consumption. For brevity, the results are presented in terms of overall effects, which are defined as the net present values over the short and long run:

$$
x_{n p v}=x+\frac{\beta}{1-\beta} \bar{x}
$$

An analysis in terms of overall effects allows us to illustrate the solution using a simple graphical apparatus, stressing the intuition behind the impact of shocks. A more detailed analysis is presented in the Appendix.

\footnotetext{
${ }^{10}$ For brevity, the discussion focuses on the MLR and NON-MLR cases. Of course, there is an intermediary case where $\rho=1$, in which a worsening of the terms of trade is exactly offset by the switching towards home goods.

${ }^{11}$ We can show that a temporary fiscal shock simply affects the output of the country where it takes place one-for-one, leaving all other variables unchanged.
} 
Overall consumption and output are given by the interaction of two relations, which are shifted by monetary and / or fiscal shocks. The first is a negative relation between overall consumption and output:

$$
\begin{aligned}
y_{n p v}-y_{n p v}^{*}= & -\frac{\rho}{\sigma}\left(1-\beta \frac{\varpi \rho c_{0}}{1+\varpi \rho c_{0}}\right)\left(c_{n p v}-c_{n p v}^{*}\right) \\
& +\rho c_{0}\left(\bar{m}-\bar{m}^{*}\right)+\left(1-\beta \frac{\varpi \rho c_{0}}{1+\varpi \rho c_{0}}\right) \frac{\bar{g}-\bar{g}^{*}}{1-\beta}
\end{aligned}
$$

(9) reflects the negative relation between output and the terms of trade, the effect of real balances in the short run, and the trade-off between consumption and effort in the long run.

At any horizons, (4) and (5) imply that output is negatively related to the terms of trade, a feature that we refer to as the consumption switching effect:

$$
y-y^{*}=-\rho c_{0}\left(p^{h}-p^{f}\right)+\left(\bar{g}-\bar{g}^{*}\right), \bar{y}-\bar{y}^{*}=-\rho c_{0}\left(\bar{p}^{h}-\bar{p}^{f}\right)+\left(\bar{g}-\bar{g}^{*}\right)
$$

Intuitively, an improvement in the terms of trade by definition raises the price of home goods relative to foreign goods in all countries, inducing consumers to substitute foreign goods for home goods. The sensitivity of this consumption switching effect is given by the cross-country substitutability $\rho$ : a given change in the terms of trade has a larger consumption switching effect the more substitutable home and foreign goods are.

The negative relation between output and consumption (9) reflects two mechanisms. The first, which operates in the short run, is the real balances effect through the money demand (3) and its foreign counterpart:

$$
\left(\bar{m}-\bar{m}^{*}\right)-s=\frac{1}{\sigma c_{0}}\left(c-c^{*}\right)
$$

Intuitively, consumption is positively related to real balances. Holding nominal balances constant, a rise in consumption requires a fall in the price level which occurs through an appreciation of the home currency (as $p=$ $(1-n) s$ and $\left.p^{*}=-n s\right)$. This appreciation in turns improves the terms of trade (as $p^{h}-p^{f}=s$ ), thereby reducing output through the consumption switching effect.

The other mechanism underlying (9) is given by the optimal price setting given by (6). It reflects the consumption-effort trade off, and operates only 
in the long run:

$$
-\frac{1}{\sigma c_{0}}\left(\bar{c}-\bar{c}^{*}\right)+\left(\bar{p}^{h}-\bar{p}^{f}\right)=\varpi\left(\bar{y}-\bar{y}^{*}\right)
$$

This relation negatively relates output and consumption through two complementary links. First, a rise in output involves a rise in effort, hence a higher marginal cost of effort due to the convexity of the effort cost in (1). ${ }^{12}$ Holding the terms of trade constant, consumption must fall in order to maintain the ratio between the marginal cost of effort and the marginal utility of consumption. Second, a rise in output requires a worsening of the terms of trade through the consumption switching effect. (6) shows that this worsening must be matched by a higher ratio between the marginal utility of consumption and the marginal cost of effort, resulting in a fall in consumption.

The relation (9) is shifted by monetary and fiscal shocks. The direct impact of monetary shocks comes through the short run real balances effect. Holding consumption constant, a rise in nominal balances must be offset by a rise in the price level through a depreciation in the home currency. The resulting worsening of the terms of trade raises output through the consumption switching effect, leading to the positive relation between nominal balances and output in (9).

Fiscal shocks have a richer impact. (4) and (5) show that, holding the terms of trade constant, fiscal shocks are simply transmitted to output onefor-one at all horizons, an aspect that is reflected in the first part of the coefficient on fiscal shocks in (9). This is somewhat dampened by a feedback through the terms of trade in the long run. Intuitively, the direct impact of government spending raises output, hence the marginal cost of effort. Holding consumption constant, this requires an improvement in the terms of trade from (6), which reduces the output increase through the consumption switching effect. This feedback is captured by the last part of the coefficient on fiscal shocks in (9), and is absent if the cost of effort isn't convex $(\varpi=0)$.

In short, (9) captures the fact that consumption is positively related to real balances in the short run and leisure in the long run, both of which are negatively related to output.

(9) is completed by a second relation between overall consumption and

\footnotetext{
${ }^{12}$ Note that this link doesn't operate if the cost of effort is a linear $(\varpi=0)$. The second link through the terms of trade remains however valid.
} 
overall output:

$$
y_{n p v}-y_{n p v}^{*}=\frac{\rho}{\rho-1}\left(c_{n p v}-c_{n p v}^{*}\right)+\frac{1}{1-\beta}\left(\bar{g}-\bar{g}^{*}\right)
$$

(10) captures the relation between consumption and sales revenue in real terms. We refer to this mechanism to as the real revenue effect. The relation is positive if the Marshall-Lerner-Robinson condition holds, as in the MLR case.

The real revenue is simply the ratio between sales in domestic currency and the consumer price index. Holding government spending constant, (10) implies that home residents can consume more than foreign residents overall only if their real revenue increases relative to foreign residents. Note that this need not be the case at a particular horizon, because lending and borrowing is possible through the current account.

As the purchasing power parity holds, the real revenue of the home residents, relative to the real revenue of foreign residents, is given by the sum of the relative output and the terms of trade $\left(y-y^{*}+p^{h}-p^{f}\right.$ in the short run and $\bar{y}-\bar{y}^{*}+\bar{p}^{h}-\bar{p}^{f}$ in the long run). Furthermore, output and the terms of trade are negatively linked through the consumption switching effect. The sensitivity of this link, given by the cross-country elasticity $\rho$, plays a central role in determining the real revenue, as it drives the magnitude of the worsening of the terms of trade required by a given rise in output through the consumption switching effect. In the $\mathbf{M L R}$ case, an output expansion increases the real revenue, whereas it reduces it in the NON-MLR case.

(10) isn't affected by monetary shocks, but is shifted by fiscal shock. Holding consumption constant, a fiscal shock is simply transmitted one-forone to output.

Figure 1 illustrates (9) and (10), with consumption $\left(c_{n p v}-c_{n p v}^{*}\right)$ on the horizontal axis and output $\left(y_{n p v}-y_{n p v}^{*}\right)$ on the vertical axis. Figure 1 depicts the situation in the absence of any shock. (9), which reflects the consumptioneffort trade off and real balances effects, is represented by the EB locus. The real revenue effect (10) is given by the $\mathbf{R} \mathbf{R}$ locus. Given the central role of the cross-country substitutability in the real revenue channel, $\mathbf{R R}$ is drawn for the MLR, NON-MLR cases. ${ }^{13}$

\footnotetext{
${ }^{13}$ Note that $\rho$ also affects the slope of $\mathbf{E B}$, without however changing its sign. For clarity, we do not draw a different curve EB for each case. The reader may also worry whether $\mathbf{R R}$ and EB become indistinguishable in the NON-MLR case. We however
} 


\subsection{Home Welfare versus Foreign Welfare: A Gener- alized Marshall-Lerner-Robinson Condition.}

In order to assess the welfare impact of shocks, we need to balance the effects on consumption and output through a welfare metric. Note that by welfare analysis we mean whether a shock has a beneficial impact, given the initial circumstances, and not whether the possibility of shocks has a detrimental effect ex ante. The later approach requires a more complex analysis in an explicitly stochastic model, and is undertaken by Obstfeld and Rogoff (1998) and Devereux and Engel (1998).

Our setup provides us with an explicit criterion in the form of the representative consumer's utility. Taking a linear approximation of (1) we write the welfare effect for a home resident as:

$$
u=\frac{U-U_{0}}{C_{0}^{-\frac{1}{\sigma}} Y_{0}}=c_{n p v}+\frac{1}{1-\beta} \bar{g}-\frac{\theta-1}{\theta} y_{n p v}
$$

where the direct welfare impact of real balances is omitted, following Obstfeld and Rogoff (1996, 1995). (11) is derived assuming that private consumption and government spending are equally valuable at the margin:

$C_{0}^{-\frac{1}{\sigma}}=F^{\prime}\left(G_{0}\right)$. This assumption is made to scale the results. Assuming instead that government spending does not enter the utility would lower the welfare, as government spending is then essentially a waste of resources. The magnitude of such a waste being larger that the effects through the other channels of the model, the picture would be somewhat blurred. Our assumption suppresses this waste and highlights the impact of the other mechanisms in a clearer way. By combining (11) and its foreign equivalent, we derive the indifference curve along which residents in both countries are equally well off $\left(u=u^{*}\right)$ :

$$
y_{n p v}-y_{n p v}^{*}=\frac{\theta}{\theta-1}\left(c_{n p v}-c_{n p v}^{*}\right)+\frac{\theta}{\theta-1} \frac{\bar{g}-\bar{g}^{*}}{1-\beta}
$$

(12) implies a positive relation between output and consumption, along which the benefit from an increase in consumption is exactly offset by the disutility from an increase in output, hence effort. Holding the consumption constant, fiscal shocks shift the indifference curve. As government con-

assume that $\rho>1-\sigma$, which is reasonable as discussed in the Appendix. Under such an assumption, $\mathbf{R R}$ is unambiguously steeper than EB in the NON-MLR case. 
sumption enters the utility, a fiscal expansion raises welfare and has to be compensated by a rise in effort. ${ }^{14}$

In order to highlight the intuition behind the welfare results, we use (10) to write the relative welfare effect as:

$$
u-u^{*}=\frac{\rho-\theta}{\rho \theta}\left(y_{n p v}-y_{n p v}^{*}\right)+\frac{1}{\rho} \frac{\bar{g}-\bar{g}^{*}}{1-\beta}
$$

(13) is a central result of this paper, as it clearly illustrates how various adverse welfare effects can occur. Omitting fiscal shocks, we focus on the relation between output and welfare. (13) reflects the combination of two links between consumption and output. First, (10) shows that output is transformed into consumption through the real revenue effect at a rate equal to $(\rho-1) \rho^{-1}$, which captures the negative linkage between output and the terms of trade:

$$
c_{n p v}-c_{n p v}^{*}=\frac{\rho-1}{\rho}\left(y_{n p v}-y_{n p v}^{*}\right)
$$

Second, as producers charge a markup over marginal cost, exerting an additional unit of effort is equivalent to sacrificing $(\theta-1) \theta^{-1}<1$ units of consumption. In consumption units, the cost of effort is therefore given by $(\theta-1) \theta^{-1}$ times effort, and residents are better off if they receive more than this amount in additional consumption:

$$
u-u^{*}=\left(c_{n p v}-c_{n p v}^{*}\right)-\frac{\theta-1}{\theta}\left(y_{n p v}-y_{n p v}^{*}\right)
$$

Intuitively, the cost of effort in consumption units reflects the markup due to monopolistic competition. This markup is in turn a function of the price elasticity that firms face, which is equal to $\theta$. If $\rho=\theta$, as in Obstfeld and Rogoff $(1996,1995)$, the benefit from consumption exactly offsets the cost of effort, and there is no welfare difference across countries.

The relative welfare effect can therefore be interpreted as reflecting a generalized Marshall-Lerner-Robinson condition. As shown by (10), a given output expansion raises consumption, relative to the foreign country, if $\rho>1$, which is the usual MLR condition. The expansion however raises welfare, relative to the foreign country, only if $\rho>\theta>1$. The relevant threshold for the cross-country elasticity is therefore different depending on whether we analyze the effect on consumption (the usual MLR condition) or welfare (the generalized MLR condition).

\footnotetext{
${ }^{14}$ In the case where government spending is wasteful, the last term is of course omitted.
} 
When $y_{n p v}-y_{n p v}^{*}$ is positive, the residents of the home country are worse off, relative to their foreign counterparts, if $\rho<\theta$. The worsening of the terms of trade required to absorb the rise in output through the consumption switching effect is such that home residents cannot afford enough consumption to offset the extra cost of effort. The additional effort therefore costs more in consumption units than it generates through the real revenue effect.

As pointed out by Obstfeld and Rogoff (1998), the difference between the cross-country and the within-country elasticities of substitution generates an externality. Focusing on the home country, (4) shows that the relevant price elasticity for an individual firm is $\theta$, as it can only changes its own price, $P^{h}(k)$, and its impact on the price indexes $P^{h}, P, P^{* h}$ and $P^{*}$ is negligible. The firm then chooses a markup $\theta(\theta-1)^{-1}$ over its marginal cost. The problem faced by a planner who coordinates the firms' price setting in the country is however different. By analogy to an individual firm's choice, we consider that the planner ignores the effect of her choices on the aggregate price indexes $P$ and $P^{*}{ }^{15}$ As the planner coordinate the firms' choices, the ratio between $P^{h}(k)$ and $P^{h}$ remains constant to unity, and the relevant demand elasticity is $\rho$. The planner then chooses a markup equal to $\rho(\rho-1)^{-1}$.

As $\rho<\theta$, the planner chooses a larger markup than firms. From the planner's point of view, firms should contract output from their uncoordinated choice, as this significantly improves the terms of trade. Real revenue then rises, or falls by an extent so small that it is dominated by the reduction in effort. An output expansion is therefore adverse in relative terms, as it pushes output beyond a level that is already suboptimally large from the point of view of the planner. Note that the goal of the planner is not to reach the competitive equilibrium, which requires an output expansion, but to exploit the country's monopoly power in the most efficient way.

In this setup, the equilibrium where firms do not coordinate their choices is therefore characterized by two inefficiencies: the first is given by the existence of a markup over marginal cost, and reflects the monopolistic competition, whereas the second reflects a coordination failure among home firms

\footnotetext{
${ }^{15}$ This can easily be rationalized in the case of a small country. In the case of a large country however, such an impact wouldn't be negligible, and the reader may object to the assumption of holding $P$ and $P^{*}$ constant. The justification for doing so is that the mentioning of a planner is done simply for expositional purposes. The choice of a myopic planner, who ignores the effects on $P$ and $P^{*}$, is conceptually identical to the choice of an individual firm, and the central mechanism of the model can then be highlighted in a simple way.
} 
to exploit their monopoly power more efficiently.

In the case where $\rho=\theta$, there is no incentive for a planner to alter the uncoordinated equilibrium, as firms perceive the right demand elasticity. If $\rho>\theta$, the situation is reversed: the elasticity for the planner is larger than for the firms, which set their markup at an inefficiently high level. Because of the high sensitivity of output with respect to the terms of trade, the planner lowers the markup below $\theta(\theta-1)^{-1}$, which rises the real revenue by enough to offset the additional cost of effort.

(13) also shows that holding output constant a fiscal expansion is beneficial, and affects welfare through two effects. First, government purchases have a direct positive welfare effect. Second, a fiscal expansion in the home country reduces the amount of home goods available for private consumption worldwide. An improvement of the home terms of trade is then required to adjust the pattern of consumption through the consumption switching effect. The improvement of the terms of trade then affects consumption through the real revenue effect (10). In the NON-MLR case the improvement of the terms of trade is so large that the real revenue rises and consumption increases, amplifying the direct welfare impact of the fiscal shock. In the MLR case, the improvement of the terms of trade remains small, and the real revenue decreases. The ensuing reduction in consumption reduces the direct beneficial impact of the fiscal shock. Note however that this dampening is never large enough to revert the direct effect of the fiscal shock.

Having established our analytical framework, we focus on the monetary and fiscal shocks separatively. Without loss of generality, we consider shocks that are expansionary in the home country, relative to the foreign country: $\bar{m}-\bar{m}^{*}>0, \bar{g}-\bar{g}^{*}>0$.

\subsection{The Effects of an Unexpected Monetary Shock}

A monetary expansion does not affect $\mathbf{R R}$, but shifts EB upwards through its effect on the nominal balances, as illustrated in figure 2. Overall output unambiguously increases, whereas the consumption effect depends of the degree of cross-country substitutability. From the detailed solution given in the Appendix, we can show that in overall terms the terms of trade always worsen. In the MLR case, this worsening remains small and consumption increases. In the NON-MLR case the worsening of the terms of trade is large enough to reduce real revenue and consumption.

The Appendix indicates the exact solution for the variables of the model. 
It shows that the magnitude of the exchange rate depreciation is inversely related to the degree of cross-country substitutability. In addition, the long run effects depend on the cross-country substitutability as the home country runs a current account surplus in the MLR case, but a current account deficit in the NON-MLR case. Intuitively, the terms or trade improve in the long run, relative to the short run, in both cases. ${ }^{16}$ In the MLR case, this generates a temporary rise in real revenue, and the impact on consumption is smoothed through a current account surplus. In the NON-MLR case by contrast, there is a temporary reduction of real revenue, and consumption is smoothed through a current account deficit.

Figure 2 also illustrates the indifference curve (12), denoted by $\mathbf{U}$. We focus on the case where there cross-country substitutability is smaller than the within-country substitutability $(\rho<\theta)$, implying that $\mathbf{R R}(\mathrm{MLR})$ is steeper than $\mathbf{U}$. At any point located above $\mathbf{U}$ home residents are worse off than foreign residents $\left(u<u^{*}\right)$. We can clearly see that this is unambiguously the case when $\rho<\theta$. If $\rho=\theta, \mathbf{U}$ and $\mathbf{R R}$ are identical and the welfare effect is the same in both countries, as in Obstfeld and Rogoff $(1996,1995)$. If $\rho>\theta$, $\mathbf{U}$ is steeper than $\mathbf{R R}$ and home residents are better off relative to foreign residents.

\subsection{The Effects of an Unexpected Fiscal Shock}

A fiscal shock shifts RR, U and EB upwards, as illustrated in figure 3. At can be seen from $(10)$, $\mathbf{R R}$ shifts by $\left(\bar{g}-\bar{g}^{*}\right)(1-\beta)^{-1}$. We can show that $\mathbf{U}$ shifts by more than $\mathbf{R R}$ which shifts by more than EB. A fiscal expansion in the home country always raises output. In addition, we can establish that output always increases by less than the fiscal shock, as can be seen in figure 3: $y_{n p v}-y_{n p v}^{*}<\left(\bar{g}-\bar{g}^{*}\right)(1-\beta)^{-1}$. This leads to an overall improvement in the terms of trade. In the MLR case, the reduction of output available for consumption isn't offset by the improvement of the terms of trade, leading to a reduction in real revenue and consumption. In the NON-MLR case, the reduction of output net of government purchases leads to such an improvement in the terms of trade that real revenue and consumption increase.

\footnotetext{
${ }^{16}$ In the MLR case, the terms of trade worsen in the short run, but improve in the long run. In the NON-MLR case they worsen at both horizon, the short run effect being however larger.
} 
The detailed solution in the Appendix also shows the MLR case is characterized by an exchange rate depreciation and a current account surplus, the opposite being true in the NON-MLR case. Intuitively, the terms of trade always improve in the long run, relative to the short run, ${ }^{17}$ leading to a similar current account effect as discussed in the case of a monetary shock.

Turning to the welfare effect, we clearly see from figure 3 that the intersection of $\mathbf{R R}$ and $\mathbf{E B}$ is always below $\mathbf{U},{ }^{18}$ which implies that the home residents are better off than the foreign residents. Intuitively, the home residents can always choose to raise their effort in order to meet the extra demand without changing any other of their choice variables. As the economy is originally at a state where the marginal utility of government consumption exceeds the marginal cost of output, simply meeting the extra demand is welfare improving for the home residents. ${ }^{19}$

Interestingly, the welfare consequences of an expansionary shock are sharply different depending on the exact source of the shock. Whereas a monetary shock can lower the welfare of home residents, relative to foreign residents, a fiscal shock always have the opposite effect.

\section{Can Expansionary Shocks be Detrimental?}

Our welfare analysis so far has focused on the difference between the home and the foreign countries, and shown that home residents can be adversely affected in relative terms $\left(u<u^{*}\right)$. In order to assess whether they can be adversely affected in absolute terms $(u<0)$, we need to combine the cross-country differences with the worldwide effects.

Without loss of generality, we focus on shocks in the home country $\left(\bar{m}^{*}=\bar{g}^{*}=0\right)$ and consider expansionary shocks, i.e. shocks that have a beneficial welfare effect in a closed economy: $\bar{m}>0, \bar{g}>0$. The detailed

\footnotetext{
${ }^{17}$ In the MLR case, the terms of trade worsen in the short run and improve in the long run. In the NON-MLR case, they improve at both horizons, the effect being larger in the long run.

${ }^{18}$ The reader can check that this is indeed the case for any non negative value of $\rho$.

${ }^{19}$ If government spending does not enter the utility, the indifference curve $\mathbf{U}$ goes through the origin in figure 3. A fiscal shock then reduces the welfare of home residents in the MLR case. Note that this isn't necessarily true in the NON-MLR cases, as it is then possible for $\mathbf{R R}$ and $\mathbf{E B}$ to intersect below $\mathbf{U}$. This occurs if the improvement in the terms of trade generates enough additional real revenue to offset the waste from government spending.
} 
analysis presented in the Appendix shows that a monetary shock can have an adverse effect either on the home or the foreign country. The home country experiences an beggar-thyself effect $(u<0)$ if the following condition is met:

$$
n<\frac{\theta-\rho}{\sigma+(\rho-1)\left(1-\beta \frac{\varpi \rho c_{0}}{1+\varpi \rho c_{0}}\right)+(\theta-\rho)}<1
$$

(14) clearly cannot be satisfied if there is more substitutability across countries than within countries $(\rho \geq \theta)$, as the home residents are then better off than the foreign residents. If $\theta>\rho$ however, the ratio in (14) is between 0 and $1,{ }^{20}$ and the possibility of a beggar-thyself problem cannot be excluded. Such a problem is more likely if the home country is small (low value of $n$ ), there is little cross-country substitutability (low value of $\rho$ ) or the economy is already close to the competitive outcome (high value of $\theta$ ).

If the home country is small, the worldwide impact of its monetary expansion is negligible and only the adverse terms-of-trade effect remains. Note that a small country can be adversely affected even if $\rho$ and $\theta$ are relatively close. If home and foreign goods are poor substitutes, the magnitude of the terms-of-trade effect is amplified, as output isn't very responsive. Intuitively, the role of the cross-country substitutability in generating a beggar-thyself effect can be understood as follows: the worsening of the home terms of trade doesn't result in any sizable shift of world consumption towards home goods. The residents of the home country therefore do not benefit from a significantly larger revenue, but face a higher cost if imports, which they cannot substitute away from. Foreign residents on the other hand benefit as the cost of their imports is reduced. In the extreme case of non-substitutability $(\rho \rightarrow 0)$, there is a beggar-thyself problem if $n<\theta(\theta+\sigma-1)^{-1}$, which is close to 1: even a very large country is adversely affected by its monetary expansion when there is little cross-country substitutability. If the economy is already operating close to the competitive outcome, the initial distortion due to monopolistic competition is negligible, and the worldwide welfare gain from a monetary expansion is close to zero.

In addition, a monetary expansion in the home country results in a 'beggar-thy-neighbor' problem $\left(u^{*}<0\right)$ if:

$$
\rho-\theta>\sigma+(\rho-1)\left(1-\beta \frac{\varpi \rho c_{0}}{1+\varpi \rho c_{0}}\right)
$$

\footnotetext{
${ }^{20}$ Assuming that $\rho-1>-\sigma$ ensures this result.
} 
(15) clearly cannot hold if there is less substitutability across countries than within countries $(\rho \leq \theta)$, as the welfare effect is then larger in the foreign country. If $\rho \rightarrow \infty$ however, (15) holds. Intuitively, there is a beggarthy-neighbor problem when the cross-country substitutability is high because the worsening of the home terms of trade results in a massive shift of world consumption towards home goods. This generates a fall in revenue for foreign residents, which dominates the beneficial effect through imported deflation. Foreign residents benefit as they experience a rise in their revenue and can easily substitute away from more expensive imports.

Turning to a fiscal expansion in the home country, the Appendix shows that the home welfare is always increased when government and private consumption are equally valuable at the margin. A fiscal shock therefore does not generate a beggar-thyself effect. On the other hand, the foreign country is always adversely affected through a beggar-thy-neighbor problem. ${ }^{21}$

The beggar-thy-neighbor effect is stronger when the cross-country substitutability is low. This occurs because the amount of worldwide output available for private consumption is always reduced: $y_{n p v}^{w}<g_{n p v}^{w} \Rightarrow c_{n p v}^{w}<0$. In addition, the foreign country experiences a deterioration of its terms of trade. In the MLR case, this raises its real revenue, which alleviates the reduction in consumption, without reverting it. In the NON-MLR case, the real revenue of foreign residents decreases, amplifying the decrease in consumption. The adverse effect on foreign residents is therefore magnified by a low degree of cross-country substitutability, which is the opposite of the situation under a monetary shock. Intuitively, this occurs because the overall home terms of trade always worsen under a monetary expansion, whereas they always improve under a fiscal expansion.

The fiscal expansion raises output in the home country, along with the total consumption, public and private. In the MLR case, the improvement of the home terms of trade reduces the real revenue, amplifying the impact of the worldwide decrease in private consumption. In the NON-MLR case, the real revenue of home residents raises, which alleviates the consequence of the fall in worldwide consumption. In addition, the sum of private and public consumption in the home country always increases by more than the home output, as the change in private consumption does not fall entirely on home

\footnotetext{
${ }^{21}$ If government spending does not enter the utility, we can show that the results for the foreign country remain valid, whereas the home country can be better off if there is little cross-country substitutability.
} 
goods. If government spending enters the utility function, home residents are clearly better off.

\section{A Numerical Example}

This section illustrate our findings through a numerical example. Following Betts and Devereux (1996b), we consider prices to be set for a year and choose $\beta=0.94$, leading to a steady state real interest rate of $6 \%$. The value of the elasticity of substitution within a country, $\theta$, is set at 6 , which implies a markup of 20\%, following Rotemberg and Woodford (1992). We choose a value of 1 for $\sigma$, which is consistent with Beaudry and van Wincoop (1996), ${ }^{22}$ and consider the case of a quadratic cost of effort $(\varpi=1) \cdot{ }^{23}$ The share of private consumption $c_{0}$ is set equal to 0.8 , which is consistent with U.S. data (Statistical Abstract of the United States (1997), table 692). We present the results for various values of the elasticity of substitution across countries $\rho$. The size of the home country, $n$, is set to 0.5. Without loss of generality, we focus on expansionary shocks in the home country, normalizing them to unity $(\bar{m}=1$ or $\bar{g}=1)$. For brevity, we focus on the welfare results of the model. $^{24}$

Figures 4 and 5 present the welfare effects following a monetary and a fiscal shock respectively. For comparison, the welfare effect in a closed economy is also presented. In the case of a monetary shock (figure 4), we see that both countries are better off to the same extent when the cross-country and withincountry of substitutability are the same $(\rho=\theta)$, as pointed out by Obstfeld and Rogoff $(1996,1995)$. If there is more substitutability across countries than within countries $(\rho>\theta)$, foreign residents are worse off, relative to home residents, and also in absolute terms if the degree of cross-country substitutability is large enough. ${ }^{25}$ If there is less substitutability across countries than within countries $(\rho<\theta)$, a 'beggar-thyself' phenomenon is possible. Overall, there is a wide range of values for the cross-country substitutability for which either the home or the foreign country is adversely affected, while

\footnotetext{
${ }^{22}$ This ensures that $\rho-1+\sigma \geq 0$ for any value of $\rho$.

${ }^{23}$ Our results would be similar with another value of $\varpi>0$.

${ }^{24} \mathrm{~A}$ more complete set of results is available from the author.

${ }^{25}$ The threshold beyond which the foreign country experiences an adverse beggar-thyneighbor effect can be shown not to depend on the size of the home country. Figure 4 shows that the threshold value of $\rho$ (8.36) is relatively close to $\theta$.
} 
the other country enjoys a beneficial effect larger than if it was a closed economy. This shows that cases where both countries benefit from a monetary shock appear to be more of an exception than the rule.

In the case of a fiscal shock (figure 5), the home country always benefits at the foreign country's expense in absolute terms. The beggar-thy-neighbor effect is stronger the lower the degree of substitutability across countries. If government spending does not enter the utility of home residents, the curve for the home country is shifted downwards in figure $5,{ }^{26}$ and home residents are likely to be worse off because of the wasteful aspect of government spending. Note however that the curve for the foreign country does not move, and there is still a beggar-thy-neighbor effect that is unrelated to the wasteful dimension of government spending, and is only a consequence of the interaction between the worldwide crowding out of private consumption and the improvement of the home terms of trade.

Figures 4 does not contrast the situation depending on the size of the home country. (14) however shows that the possibility of a beggar-thyself effect following a monetary shock depends on this size. This point is presented in figure 6, which illustrates the combinations of $n$ and $\rho$ resulting in such an adverse effect. A beggar-thyself problem occurs for any combination of $\rho$ and $n$ located below the curve. Such a problem is always possible as long as $\rho<\theta$. If the home country is very small, it is adversely affected even if there isn't much difference between the degrees of substitutability across and within countries. This indicates that the finding of an equally beneficial welfare effect in both countries by Obstfeld and Rogoff $(1996,1995)$ is true only if $\rho$ is exactly equal to $\theta$ : if $\rho$ is close to $\theta$, the welfare effects will be quantitatively close in both countries, but qualitatively different, as the effect is negative for the home country and positive for the foreign country. Furthermore, a beggar-thyself effect isn't limited to a small country. If $\rho=1$ or $\rho=2$ for example, such an effect occurs if the home country represents less than $83 \%$ and $74 \%$ of the world respectively. This suggests that taking the case of a closed economy as an approximation of a large open economy can be misleading when domestic and imported goods are poor substitutes.

\footnotetext{
${ }^{26}$ The extent of the shift is equal to $(1-\beta)^{-1} \bar{g}=16.67$.
} 


\section{Conclusion}

This paper evaluate the role of the degree of substitutability between goods produced in different countries in the transmission of shocks, building on previous work by Obstfeld and Rogoff $(1996,1995)$. Their finding that all countries benefit from a monetary shock appears to be more of an exception than the rule, and the exact nature of the shock plays an important role.

If the cross-country substitutability is high, an monetary expansion generates a large reallocation of world demand towards home goods, raising the real revenue of home residents. The corresponding reduction of foreign residents revenue can be large enough to result in an adverse beggar-thy-neighbor welfare effect. On the other hand, if the cross-country substitutability is low, the reallocation of world demand towards home goods is small, dampening the change in real revenue. In addition, home residents pay a higher price for imports they cannot substitute away from, and an adverse beggar-thyself welfare effect is possible. We also find that beggar-thyself effects are not limited to small countries, though they are more likely for them. Our results suggest that approximating a large open economy by a closed economy should be done with caution.

A boost in the demand for home goods resulting from a fiscal expansion generates a beggar-thy-neighbor problem for foreign residents. This occurs because the worsening of the foreign terms of trade can never rise their real revenue sufficiently to offset the worldwide crowding out of private consumption. If the cross-country substitutability is small, the real revenue of foreign residents actually decreases, amplifying the adverse effect of the crowding out.

The assumption of the law of one price can appear to conflict with the extensive literature casting doubt on it(Betts and Devereux (1997, 1996a,b), Engel and Rogers (1997), Engel (1997)). It is possible to extend our framework to include deviations from the law of one price, and such a step is undertaken in a companion work (Tille 1998b). Allowing for such deviations tilts the balance in favor of the country with a depreciating currency. The intuition is that a depreciation in the real exchange rate, ${ }^{27}$ implies that any real sale abroad generates a higher real return. The finding that either the home or the foreign country is adversely affected remains true however.

\footnotetext{
${ }^{27}$ The real exchange rate is defined as the nominal exchange rate times the ratio of consumer price indexes, and is different from the terms of trade.
} 
This paper shows that the popular claim that an expansion in an open economy have a beggar-thy-neighbor effect should be taken with caution. A micro-founded model shows that the an opposite effect can be true, highlighting the relevance of a solid welfare criterion in the analysis of international spillovers. 


\section{Appendix}

\subsection{Solution of the Model}

This Appendix presents the derivation of the model solution. The steps are similar to Obstfeld and Rogoff $(1996,1995)$, and we refer the reader to their contributions for more details. Worldwide variables are defined as a weighted combination of home and foreign variables, and can be written in terms of log linear approximations around the symmetric steady-state as:

$$
c^{w}=n c+(1-n) c^{*}, \bar{g}^{w}=n \bar{g}+(1-n) \bar{g}^{*}, y^{w}=c^{w}+\bar{g}^{w}
$$

Recall that all firms are identical in a given country and that the law of one price holds. We then combine linear approximations of the demands (4)-(5) in the short and the long run to obtain:

$$
y-y^{*}=-\rho c_{0}\left(p^{h}-p^{f}\right)+\left(\bar{g}-\bar{g}^{*}\right), \bar{y}-\bar{y}^{*}=-\rho c_{0}\left(\bar{p}^{h}-\bar{p}^{f}\right)+\left(\bar{g}-\bar{g}^{*}\right)
$$

In the long run, prices are adjusted and the optimal price setting equations (6) are binding. We linearize them and take the cross-country difference to obtain:

$$
-\frac{1}{\sigma c_{0}}\left(\bar{c}-\bar{c}^{*}\right)+\left(\bar{p}^{h}-\bar{p}^{f}\right)=\varpi\left(\bar{y}-\bar{y}^{*}\right)
$$

Combining (16) and (17), we obtain a negative relation between output and consumption in the long run:

$$
\left(\bar{y}-\bar{y}^{*}\right)\left(1+\varpi \rho c_{0}\right)=-\frac{\rho}{\sigma}\left(\bar{c}-\bar{c}^{*}\right)+\left(\bar{g}-\bar{g}^{*}\right)
$$

Recalling that the steady state interest rate is equal to $\beta^{-1}-1$, we use linear approximations of (7) and (8), along with (16) to write:

$$
0=\frac{1-\beta}{\beta} \frac{b}{1-n}+\frac{\rho-1}{\rho}\left[\left(\bar{y}-\bar{y}^{*}\right)-\left(\bar{g}-\bar{g}^{*}\right)\right]-\left(\bar{c}-\bar{c}^{*}\right)
$$

Taking a weighted sum of (6) we obtain the worldwide consumption and output effects:

$$
\bar{c}^{w}=-\frac{\varpi \sigma c_{0}}{1+\varpi \sigma c_{0}} \bar{g}^{w}, \bar{y}^{w}=\frac{1}{1+\varpi \sigma c_{0}} \bar{g}^{w}
$$


From a linear approximations of the Euler equation in the home country (2) and its foreign counterpart, we can show that the cross country consumption difference is the same in the short and the long run as the purchasing power parity holds:

$$
c-c^{*}=\bar{c}-\bar{c}^{*}
$$

Combining this result and the money demands (3) in both countries, in the short and the long run, we can show that there is no exchange rate overshooting:

$$
s=\bar{s}=\left(\bar{m}-\bar{m}^{*}\right)-\frac{1}{\sigma c_{0}}\left(c-c^{*}\right)
$$

In the short run, prices are fixed in the producers currency: $p^{h}=p^{* f}=0$, $p^{f}=s, p^{* h}=-s$. Combining this results with (16) and (20), we obtain a negative relation between output and consumption in the short run:

$$
y-y^{*}=-\frac{\rho}{\sigma}\left(c-c^{*}\right)+\rho c_{0}\left(\bar{m}-\bar{m}^{*}\right)+\left(\bar{g}-\bar{g}^{*}\right)
$$

Recalling that $B_{0}=0$, we combine linear approximations of (7) and (8), along with (16) to obtain:

$$
\frac{b}{1-n}=\frac{\rho-1}{\rho}\left[\left(y-y^{*}\right)-\left(\bar{g}-\bar{g}^{*}\right)\right]-\left(c-c^{*}\right)
$$

The worldwide consumption and output effects in the short run can be computed from the Euler equations and money demands, along with the worldwide results in the long run. Some algebra leads to:

$$
c^{w}=\sigma c_{0} \bar{m}^{w}, y^{w}=\sigma c_{0} \bar{m}^{w}+\bar{g}^{w}
$$

\subsubsection{Overall Solution}

Combining the short and long run relations, we can rewrite the model in terms of overall effects, which are defined as the net present values over the short and long run:

$$
x_{n p v}=x+\frac{\beta}{1-\beta} \bar{x}
$$

We combine the negative relations between output and consumption (18) and (21) to derive equation (9) in the text:

$$
y_{n p v}-y_{n p v}^{*}=-\frac{\rho}{\sigma}\left(1-\beta \frac{\varpi \rho c_{0}}{1+\varpi \rho c_{0}}\right)\left(c_{n p v}-c_{n p v}^{*}\right)+\rho c_{0}\left(\bar{m}-\bar{m}^{*}\right)
$$




$$
+\left(1-\beta \frac{\varpi \rho c_{0}}{1+\varpi \rho c_{0}}\right) \frac{\bar{g}-\bar{g}^{*}}{1-\beta}
$$

Similarly, we combine (19) and (22) to derive equation (10) in the text:

$$
c_{n p v}-c_{n p v}^{*}=\frac{\rho-1}{\rho}\left[\left(y_{n p v}-y_{n p v}^{*}\right)-\frac{1}{1-\beta}\left(\bar{g}-\bar{g}^{*}\right)\right]
$$

The overall worldwide effects can be computed as:

$$
\begin{aligned}
& c_{n p v}^{w}=\sigma c_{0} \bar{m}^{w}-\frac{\beta}{1-\beta} \frac{\varpi \sigma c_{0}}{1+\varpi \sigma c_{0}} \bar{g}^{w} \\
& y_{n p v}^{w}=\sigma c_{0} \bar{m}^{w}+\left(1+\frac{\beta}{1-\beta} \frac{1}{1+\varpi \sigma c_{0}}\right) \bar{g}^{w}
\end{aligned}
$$

The detailed solution for the various variables in the short and the long run can be derived from (18), (19), (21) and (22) as:

$$
\begin{aligned}
c-c^{*} & =\Pi_{C M}\left(\bar{m}-\bar{m}^{*}\right)+\Pi_{C G}\left(\bar{g}-\bar{g}^{*}\right) \\
s & =\Pi_{S M}\left(\bar{m}-\bar{m}^{*}\right)+\Pi_{S G}\left(\bar{g}-\bar{g}^{*}\right) \\
\frac{b}{1-n} & =\Pi_{B M}\left(\bar{m}-\bar{m}^{*}\right)+\Pi_{B G}\left(\bar{g}-\bar{g}^{*}\right) \\
\bar{p}^{h}-\bar{p}^{f} & =\Pi_{T M}\left(\bar{m}-\bar{m}^{*}\right)+\Pi_{T G}\left(\bar{g}-\bar{g}^{*}\right) \\
y-y^{*} & =\Pi_{Y S M}\left(\bar{m}-\bar{m}^{*}\right)+\Pi_{Y S G}\left(\bar{g}-\bar{g}^{*}\right) \\
\bar{y}-\bar{y}^{*} & =\Pi_{Y L M}\left(\bar{m}-\bar{m}^{*}\right)+\Pi_{Y L G}\left(\bar{g}-\bar{g}^{*}\right)
\end{aligned}
$$

where the coefficients are:

\begin{tabular}{|l|l|}
\hline$\Pi_{C M}=\frac{c_{0}}{D}(1-\beta)(\rho-1)$ & $\Pi_{C G}=-\frac{1}{D} \frac{\beta \varpi c_{0}}{1+\varpi \rho c_{0}}(\rho-1)$ \\
\hline$\Pi_{S M}=\frac{1}{D}\left(1+\frac{\rho-1}{\sigma} \frac{\beta}{1+\varpi \rho c_{0}}\right)$ & $\Pi_{S G}=\frac{1}{D} \frac{\left.\beta \varpi \varpi \rho c_{0}\right)}{\sigma(1+\varpi-1)}$ \\
\hline$\Pi_{B M}=\frac{\beta c_{0}(\rho-1)}{D}\left(1+\frac{\rho-1}{\sigma} \frac{1}{1+\varpi \rho c_{0}}\right)$ & $\Pi_{B G}=\frac{1}{D} \frac{\beta \varpi c_{0}(\rho-1+\sigma)}{\sigma\left(1+\rho c_{0}\right)}(\rho-1)$ \\
\hline$\Pi_{T M}=\frac{1}{D} \frac{\rho-1}{\sigma} \frac{1-\beta}{1+\varpi \rho c_{0}}$ & $\Pi_{T G}=\frac{1}{D} \frac{\varpi}{1+\rho c_{0}} 1+\frac{(1-\beta)(\rho-1)}{\sigma}$ \\
\hline$\Pi_{Y S M}=\rho c_{0} \Pi_{S M}$ & $\Pi_{Y S G}=\frac{1}{D} \frac{\rho-1+\sigma}{\sigma}$ \\
\hline$\Pi_{Y L M}=-\rho c_{0} \Pi_{T M}$ & $\Pi_{Y L G}=\frac{1}{D} \frac{\rho-1+\sigma}{\sigma\left(1+\varpi \rho c_{0}\right)}$ \\
\hline
\end{tabular}

and, assuming $\rho>1-\sigma$ :

$$
D=1+\frac{\rho-1}{\sigma}\left(1-\beta \frac{\varpi \rho c_{0}}{1+\varpi \rho c_{0}}\right)>0
$$




\subsection{Absolute Welfare Effects}

The analysis in terms of cross-country differences allows us to establish whether home residents can be adversely affected in relative terms $(u<$ $\left.u^{*}\right)$. In order to assess whether they are adversely affected in absolute terms $(u<0)$, we need to combine the cross-country differences with the worldwide effects.

Focusing on expansionary shocks in the home country $(\bar{m}>0, \bar{g}>0$, $\bar{m}^{*}=\bar{g}^{*}=0$ ), we use our results to write the relative welfare effect as:

$$
u-u^{*}=\frac{\rho-\theta}{\theta} \frac{c_{0}}{D} \bar{m}+\left[1+\frac{\rho-\theta}{\theta} \frac{1}{D}\left(1-\beta \frac{\varpi \rho c_{0}}{1+\varpi \rho c_{0}}\right) \frac{\rho-1+\sigma}{\sigma}\right] \frac{1}{\rho} \frac{\bar{g}}{1-\beta}
$$

Taking a weighted sum of the home and foreign variables, the worldwide welfare effect is given by:

$$
u^{w}=\frac{\sigma c_{0}}{\theta} n \bar{m}+\frac{1}{\theta}\left(1-\beta \frac{\varpi \sigma c_{0}}{1+\varpi \sigma c_{0}}\right) \frac{1}{1-\beta} n \bar{g}
$$

\subsubsection{Method}

Before analyzing each type of shock, we present the method used. ${ }^{28}$ The relative and worldwide welfare effects of a domestic shock $\bar{x}>0(\bar{x}=\bar{m}, \bar{g})$ can be written as:

$$
u-u^{*}=\Phi_{X} \Lambda_{X} \bar{x}, u^{w}=n \Phi_{X} \bar{x}
$$

where $\Phi_{X}>0$ as we consider shocks that are beneficial in a closed economy. The home and foreign welfare effects are then of the form:

$$
u=\left(1-\Lambda_{X}\right)\left(n-\frac{-\Lambda_{X}}{1-\Lambda_{X}}\right) \Phi_{X} \bar{x}, u^{*}=n \Phi_{X}\left(1-\Lambda_{X}\right) \bar{x}
$$

It is straightforward to see that if $\Lambda_{X}>1$ there is a 'beggar-thy-neighbor' problem where an expansionary shock in the home country has an adverse effect on the foreign country. Assessing the home welfare effect is more complex. We start by deriving the properties of the ratio $\frac{-\Lambda_{X}}{1-\Lambda_{X}}$ :

$$
\begin{aligned}
\lim _{\Lambda_{X} \rightarrow-\infty} \frac{-\Lambda_{X}}{1-\Lambda_{X}} & =1_{-},\left.\frac{-\Lambda_{X}}{1-\Lambda_{X}}\right|_{\Lambda_{X}=0}=0 \\
\lim _{\Lambda_{X} \rightarrow 1_{-}} \frac{-\Lambda_{X}}{1-\Lambda_{X}} & =-\infty, \lim _{\Lambda_{X} \rightarrow 1_{+}} \frac{-\Lambda_{X}}{1-\Lambda_{X}}=+\infty, \lim _{\Lambda_{X} \rightarrow+\infty} \frac{-\Lambda_{X}}{1-\Lambda_{X}}=1_{+}
\end{aligned}
$$

\footnotetext{
${ }^{28} \mathrm{I}$ am grateful to Michael Woodford for bringing this method to my attention.
} 
where a convergence to $1_{-}\left(1_{+}\right)$indicates a convergence to 1 from values below (above) 1 . Table 2 gives the signs of $u-u^{*}, u$ and $u^{*}$ for various values of the coefficient $\Lambda_{X}$ :

Table 2

\begin{tabular}{||c|c|c|c|c|c||}
\hline \hline$\Lambda_{X}$ & $1-\Lambda_{X}$ & $-\Lambda_{X} /\left(1-\Lambda_{X}\right)$ & $u-u^{*}$ & $u$ & $u^{*}$ \\
\hline \hline$<0$ & $>0$ & $0<.<1$ & $<0$ & $\begin{array}{c}<0 \text { if } n<\frac{-\Lambda_{X}}{1-\Lambda_{X}} \\
>0 \text { if } n>\frac{-\Lambda_{X}}{1-\Lambda_{X}}\end{array}$ & $>0$ \\
\hline$=0$ & $>0$ & $=0$ & $=0$ & $>0$ & $>0$ \\
\hline $0<.<1$ & $>0$ & $<0$ & $>0$ & $>0$ & $>0$ \\
\hline$=1$ & $=0$ & $\pm \infty$ & $>0$ & $>0$ & $=0$ \\
\hline$>1$ & $<0$ & $>1$ & $>0$ & $>0$ & $<0$ \\
\hline \hline
\end{tabular}

The home welfare effect is then positive, except if:

$$
n<\frac{-\Lambda_{X}}{1-\Lambda_{X}}<1
$$

in which case an expansionary shock is detrimental to the home country in absolute terms, a phenomenon that we refer to as 'beggar-thyself'.

\subsubsection{Monetary Shock}

Considering a monetary shock, we use our results to write:

$$
\Phi_{M}=\frac{\sigma c_{0}}{\theta}, \Lambda_{M}=\frac{\rho-\theta}{\sigma} D^{-1}
$$

A beggar-thy-neighbor problem then occurs if:

$$
\rho-\theta>\sigma+(\rho-1)\left(1-\beta \frac{\varpi \rho c_{0}}{1+\varpi \rho c_{0}}\right)
$$

And a beggar-thyself phenomenon requires:

$$
n<\frac{\theta-\rho}{\sigma+(\rho-1)\left(1-\beta \frac{\varpi \rho c_{0}}{1+\varpi \rho c_{0}}\right)+(\theta-\rho)}<1
$$




\subsubsection{Fiscal Shock}

Turning to a fiscal shock, some algebra leads to:

$$
\begin{aligned}
\Phi_{G} & =\frac{1}{\theta}\left(1-\beta \frac{\varpi \sigma c_{0}}{1+\varpi \sigma c_{0}}\right) \frac{1}{1-\beta} \\
\Lambda_{G} & =\left[\frac{\theta \beta \varpi c_{0}}{1+\varpi \rho c_{0}}+\frac{\rho-1+\sigma}{\sigma}\left(1-\beta \frac{\varpi \rho c_{0}}{1+\varpi \rho c_{0}}\right)\right] \frac{D^{-1}}{1-\beta \frac{\varpi \sigma c_{0}}{1+\varpi \sigma c_{0}}}
\end{aligned}
$$

We can show that if $\varpi=0, \Lambda_{G}=1$ and for any $\varpi>0$ :

$$
\lim _{\rho \rightarrow \infty} \Lambda_{G}=\frac{1}{1-\beta \frac{\varpi \sigma c_{0}}{1+\varpi \sigma c_{0}}}>1, \lim _{\rho \rightarrow 0} \Lambda_{G}>1
$$

There is a beggar-thy-neighbor problem when the cross-country substitutability is very large or small, which suggests that the foreign country is always hurt by a fiscal expansion. In addition, $\Lambda_{G}>0$, and therefore there cannot be any beggar-thyself problem, as it would require $\Lambda_{G}<0 .{ }^{29}$

\footnotetext{
${ }^{29}$ If government spending do not enter the utility, we can show that the foreign country is always worse off, whereas the home country can be better off if there is little cross country substitutability.
} 


\section{References}

[1] Bacchetta, Philippe, and Eric van Wincoop (1998). "Does Exchange Rate Stability increase Trade and Capital Flows?" Research Paper 9818, Federal Reserve Bank of New York.

[2] Backus, David, Patrick Kehoe and Finn Kydland (1994a). "Dynamics of the Trade Balance and the Terms of Trade: The J-Curve?" American Economic Review, vol. 84, pp. 84-103.

[3] Backus, David, Patrick Kehoe and Finn Kydland (1994b). "Relative Price Movements in Dynamic General Equilibrium Models of International Trade." in Handbook of International Macroeconomics, Van Der Ploeg ed., Basil Blackwell, pp. 62-96.

[4] Beaudry, Paul, and Eric van Wincoop (1996). "The Intertemporal Elasticity of Substitution: An Exploration using a US Panel of State Data." Economica, vol. 63.

[5] Betts, Caroline, and Michael Devereux (1997). "The International Monetary Transmission Mechanism: A Model of Real Exchange Rate Adjustment under Pricing-to-Market." International Financial Markets and Business Cycles conference, June 8/9 1997.

[6] Betts, Caroline, and Michael Devereux (1996a). "The Exchange Rate in a Model of Pricing-to-Market." European Economic Review, vol. 40, pp. 1007-1021.

[7] Betts, Caroline, and Michael Devereux (1996b). "Exchange Rate Dynamics in a Model of Pricing-To-Market." mimeo.

[8] Corsetti, Giancarlo, and Paolo Pesenti (1997). "Welfare and Macroeconomic Interdependence." NBER Working Paper $630 \%$.

[9] Devereux, Michael, and Charles Engel (1998). "Fixed vs. Floating Exchange Rates: How Price Setting Affects the Optimal Choice of Exchange-Rate Regime." University of Washington, mimeo

[10] Engel, Charles (1997). "Accounting for U.S. Real Exchange Rate Changes." University of Washington, mimeo. 
[11] Engel, Charles, and John Rogers (1997). "How Wide is the Border?" American Economic Review, vol. 86, pp. 1112-1124.

[12] Faruqee, Hamid (1996). "Real Exchange Rates and the Pattern of Trade: Comparative Dynamics for North and South." Journal of International Money and Finance, vol. 15, pp. 313-336.

[13] Fernald, John, Hali Edison and Prakash Lougani (1998). "Was China the first Domino? Assessing Links between China and the Rest of Emerging Asia." International Finance Discussion Paper \# 604, Board of Governors of the Federal Reserve System.

[14] Hau, Harald (1998). "Exchange Rate Determination: The Role of Factor Price Rigidities and Nontradables." Journal of International Economics, forthcoming.

[15] Lane, Phillip (1998). "The New Open Economy Macroeconomics: A Survey." Trinity College Dublin, mimeo.

[16] Nurkse, Ragnar (1944). International currency experience. Lessons of the inter-war period. Geneva, League of Nations.

[17] Obstfeld, Maurice, and Kenneth Rogoff (1998). "Risk and Exchange Rates." Princeton University, mimeo.

[18] Obstfeld, Maurice, and Kenneth Rogoff (1996). Foundations of International Macroeconomics, chapter 10, MIT press.

[19] Obstfeld, Maurice, and Kenneth Rogoff (1995). "Exchange Rate Dynamics Redux." Journal of Political Economy, vol. 103, pp. 624-659.

[20] Rogers, John (1997). "Monetary Shocks and Real Exchange Rates." Federal Reserve Board, mimeo.

[21] Rotemberg, Julio, and Michael Woodford (1992). "Oligopolistic Pricing and the Effects of Aggregate Demand on Economic Activity." Journal of Political Economy, vol. 100, pp. 1153-1207.

[22] Statistical Abstract of the United States (1997), Bureau of the Census, Washington D.C., October 1997. 
[23] Tille, Cédric (1998a). "The International and Domestic Welfare Effects of Monetary Shocks under Pricing-to-Market." second chapter, Ph.D.. dissertation, Princeton University.

[24] Tille, Cédric (1998b). "The Welfare Effects of Monetary Shocks under Pricing-to-Market: A General Framework." third chapter, Ph.D.. dissertation, Princeton University.

[25] Warnock, Francis (1998). "Idiosyncratic Tastes in a Two-Country Optimizing Model: Implications of a Standard Presumption." International Finance Discussion Paper 631, Board of Governors of the Federal Reserve System.

[26] Zhu, Ning (1998). "Exchange Rate Overshooting: between Nominal and Real." Deutsche Bank, mimeo. 